\title{
Delpech and the origins of occupational psychiatry
}

\author{
R R O'Flynn, H A Waldron
}

\begin{abstract}
Auguste-Louis Delpech (1818-80) has been remembered principally as the author of the first detailed description of the serious consequences of exposure to carbon disulphide. A close reading of his work suggests that his reputation has been seriously undervalued. The subsequent development of occupational psychiatry, with its emphasis on the distinction between the organic and the functional, may be traced through publications on carbon disulphide. It is argued that a contemporary approach to occupational psychiatry is long overdue.
\end{abstract}

On peut dire que le sulfure asassine; il tue l'homme, il lui fait perdre toute dignite tout respect de soi meme. Patient Monsieur B quoted by Delpech ${ }^{1}$

In the practice of occupational psychiatry one of the central problems is to relate toxic exposures to the development of psychological symptoms. We are even now unable to understand the psychopathological connections between "intoxication" and the phenomena of confusional states whereas for many occupational physicians "functional" disturbances of bodily function are virtually equivalent to deliberate malingering.

Psychiatry has always been engaged in controversy to such an extent that historical arguments are forgotten and lessons once learnt must be relearnt. The quite opposing views of Delpech and Charcot that form the basis of this paper are expressed even now in discussions of the relative importance of "organic" and functional factors in the aetiology of occupational disease.

Charcot is well known as one of the major figures in the development of neurology whereas Delpech is remembered, if at all, for his work on the adverse effects of carbon disulphide.

\footnotetext{
Department of Psychiatry, Guy's Hospital, London SE1 9RT

R R O'Flynn

Occupational Health Department, St Mary's Hospital, London W2 1NY

$\mathrm{H} A$ Waldron
}

\begin{abstract}
Auguste-Louis Delpech
Delpech was born in Paris on 3 August 1818, the son of a doctor in the Falbourg St Germain. He qualified in medicine from the faculty in 1840 having been a pupil of Trousseau. By an irony that will become evident later, his doctoral thesis, which was accepted in 1846, was entitled "Des spasmes musculaires idiopathiques et de la paralysie nerveuse essentielle" and was apparently concerned with what would later be described as hysteria. He became a professor in the faculty of medicine in 1847 with a work on the nosology of fevers. At the age of 29 he was appointed chef de clinique at L'Hotel Dieu and in 1852 physician to the Central Paris Hospitals.

Between 1856 and 1863 he published his work on carbon disulphide that is discussed below. His later work included reports on trichinosis and pork butchery, industrial diseases associated with chromates, and accounts of public health during the siege of Paris in 1870.

As Zeldin has pointed out, the medical profession in France throughout the nineteenth century exercised considerable political power. ${ }^{2}$ Delpech was thus following a tradition in becoming a city councillor in 1876 having been awarded the Legion d'Honneur in 1866. He died of angina pectoris (or a stroke) while hunting on 5 September $1880 .^{3}$

As a professor in the University of Paris he occupied the central ground of the profession: throughout the nineteenth century the Paris School vigorously propounded scientific rationalism (particularly detailed experimental observations) as opposed to the school of Montpellier which espoused a philosophical vitalist attitude to medicine. ${ }^{2}$ The work on carbon disulphide admirably demonstrates the former approach.
\end{abstract}

\section{Carbon disulphide and vulcanisation}

Carbon disulphide was used first in medicine for treating various illnesses, as a local and general anaesthetic, and as a solvent in the compounding of medicines. Its main industrial uses since the middle of the nineteenth century, however, have been in two processes, the vulcanisation of rubber and the xanthation of viscose rayon.

Rubber had been used in the new world for many years, moulded into household objects or for waterproofing cloth. After its introduction into Europe it remained essentially a curiosity since uncured rubber hardens and cracks at low temperature and decom- 
poses and perishes in sunlight or heat. Its widespread use was made possible when Charles Goodyear developed vulcanisation in 1841: after considerable experimentation he demonstrated that if rubber was heated when mixed with flowers of sulphur it was rendered resistant not only to temperature but also to solvents that could dissolve the gum in its native state. Thomas Hancock in 1842 introduced an alternative system of hot curing in which the rubber was immersed in molten sulphur.

These processes are suitable for manufacturing large or solid items but small articles and thin strips of rubber tended to char. Alexander Parkes in a patent of 1846 described a novel method which he called cold curing: rubber was exposed to sulphur chloride in a dilute solution in either naphtha or carbon disulphide. The latter was generally adopted as it produced further swelling of the rubber, thus speeding up the process. Until the 1880 s this process was used to produce a wide variety of products including gloves, balloons, ${ }^{4}$ and what Delpech describes as "ce produit . . . industriellement consacre de preservatif, indique suffisamment l'usage" - that is, condoms.

In 1890 the method of making artifical silk (viscose rayon) from the cellulose of wood pulp was introduced. The central process in this is the reaction between cellulose and carbon disulphide to form cellulose xanthate which takes place in sealed vessels and generates considerable heat. Subsequently the viscose thus produced is extruded and woven into fabric.

The hazards to health are, of course, quite different. In the early rubber industry large vats of the curing mixture were open to the environment to allow the rubber to be dipped in, initially by hand. In the rayon process it is the cleaning out of the churns and the further processing of the viscose that expose the worker to the solvent. In the first the concentration of vapour was, one assumes, constantly high, varying little during the day whereas in the second high exposures occurred infrequently in the working day. Common to both industries was the risk of fire.

According to Hunter, Payan directed attention to the danger to workers in $1851,{ }^{5}$ but it was Delpech's papers of 1856 and 1863 that represented the first detailed account of the consequences to health of occupational exposure to carbon disulphide. This was less than five years after the widespread use of the solvent in large scale industry.

Une note sure les accidents qui développe chez les ouvriers on caoutchouc, l'inhalation de sulfure de carbone ${ }^{6}$

In his presentation to the Académie de Médecine on 15 January 1856 Delpech noted that every bodily system could be affected in some way by carbon disulphide, although the commonest symptoms were psychological:

Troubles intellectuels-Affaiblissement de la memoire; vague et confusion dan les idées. Access alternatifs de gaieté folle et d'emportement maniaque. Insomnie; agitation plus ou moins vives; rêves pênibles; reveils en sursant la nuit. Le jour, somnolence, abattement, état de torpeur et d'inertie.

The patients experienced constant headaches, dizziness, and itching. Occasionally loss of sensation or analgesia developed. Delpech had, rarely, observed increased sexual desire but frequently complete impotence developed. Affected individuals were prone to cramps and shaking of the limbs and often developed paralysis and atrophy; the muscles, however, continued to contract when electrically stimulated. He emphasised the disturbances of the musculoskeletal system, especially of the legs.

The workers were so saturated in the solvent that their breath and urine smelt of it strongly. ${ }^{2}$ If they were not removed from the source of it they would become so weak and anaemic that their lives were threatened. Delpech further considered the actions that might prevent or combat the poisoning. Only a change of work could help the afflicted workers, combined with personal "sobriety." For prevention, he advocated well ventilated factories in which workers would not eat or sleep, greater separation of the various processes from one another, and the provision of a largely meat diet for the healthy workers.

Accidens (sic) que développe chez les ouvriers en caoutchouc l'inhalation du sulfure de carbone en vapeur ${ }^{7}$

Whereas the communications to the Académie de Médecine served to establish carbon disulphide poisoning as an entity, Delpech's own success would have depended on his report reaching the widest possible number of colleagues: this was possible using the newspapers regularly directed at the members of the medical profession.

A longer account of his findings was published "from the proofs" of a paper in L'Union Médicale in May 1856. It starts with an account of the illness of Victor Delacroix then aged 27 who had been working in the cold curing room of a rubber works since 1853. In the three months before his admission to hospital he had developed several disabling symptoms with trembling and shaking of the limbs and deafness so pronounced that people shouted into his ears to make him hear. His memory had failed so completely that he lost items put down only moments before. As was often observed, his sleep was grossly disturbed by terrible dreams. His digestion was ruined and he had lost all sexual drive and function; his wife had left him even though she herself was ill.

On examination Delpech found him to be prematurely aged, walking with a stick, his legs 
wasted and weak. The extensors, particularly of the leg, were more affected than the flexors but neither was spared; the contraction in response to a galvanic current was unimpaired.

He was given electrotherapy, sulphur baths, and medications containing iron and nox vomica that gradually restored him so that he was able to recuperate in the country far from his work. Only his headaches and his impotence did not improve substantially.

Repeatedly throughout the account, and in the synopsis that follows it, Delpech emphasised that the poisoning produced by carbon disulphide resulted in gross disruption of all the bodily symptoms; indeed the more closely he examined his patients, the more he found in their symptoms.

In this work he formulated the course and the symptomatology of the disease in terms of excitement succeeded by suppression of each physiological system. In the late 1850 s, however, his views underwent a change: indeed this might account for the delay between his preliminary communications and the publication of the famous monograph. His earlier view appears to have been that the solvent diminished the operation of the body. He therefore found analogies with other toxic substances such as lead and alcohol rather than boldly claiming that a unique illness had been described: the change of view led directly to the title of the 1863 monograph (l'intoxication spéciale).

\section{Recherches sur l'intoxication spéciale que détermine le sulfure de carbone ${ }^{1}$}

Delpech's major review, the monograph to which most other authors have since referred, was derived from a communication to the Académie Impériale de Médecine in 1861. In it Delpech attempted to produce a synthetic account of the effects of the solvent in one particular group of workers in the inflated rubber industry, drawing on clinical account, the results of animal experiments, and therapeutic advances. The account is illustrated with 23 histories of men, women, and children showing various aspects of carbon disulphide poisoning. These are vivid, often dramatic vignettes, ranging from a few sentences to several pages.

Delpech chose the inflated rubber industry because it allowed him to test his previous observations. It had the other advantage that each worker tended to be employed at different times in different aspects of the trade.

Quantities of rubber were placed in large vessels and were blown into shapes either directly by the worker using a small tube or by special machines. They were dried, often in the same rooms or nearby in currents of air until all the solvent had evaporated. The workers were thus exposed to carbon disulphide throughout the day. The process also involved smaller quantities of sulphur chloride and the talcum powder in which the condoms were dipped. There were hundreds of such factories in Paris, in all of which most of the workers were ill.

Delpech's experience had led him to believe that there were two different courses in the development of carbon disulphide poisoning: one presented rapidly, in some cases after only a few hours, the other was much slower to develop and more chronic. Delpech's main attention was on the slow form, largely because he could identify phases within it more readily.

He noted that the acute intoxication had two phases: the first that of excitement followed invariably by collapse in which state a proportion of patients remained. Each bodily system went through this period of stimulation followed by a decline of function yet each did so at a different rate according, he assumed, to individual physiological variation, which led to the bewildering number of clinical presentations.

The illness was always preceded by a headache that came on initially after finishing work. It would occasionally start suddenly with terrible bursting pain whereas on other occasions it had a crushing quality.

The patients would then develop tingling (fourmillements) and itching, particularly of the scrotum. Eventually, however, mental excitement would begin, often shown most notably in extreme talkativeness. As Madame A told him, "Quoique j'eusse la plus grand difficulté à trouver les mots dont $\mathrm{j}$ 'avais besoin, j'avais un flux de paroles intarissable. Je me sentais déraisonner sans pouvoir m'arrêter." With the pressure of speech came violent fluctuations of mood ranging from happiness and elation to anxious foreboding. A few became frankly insane. One, for example, was subject to "des terreurs sans raison, la croyance à des crimes imaginaires dont il se serait rendu coupable, des hallucinations de la vue et de l'ouie, une agitation maniaque extrème."

Occasionally epileptiform convulsions formed a considerable part of the clinical picture. Only two cases discussed in the monograph had ever experienced convulsions and in both they had occurred for only a short period in the most severe intoxication and disappeared rapidly.

The patients were subject to endless agitation, insomnia, and absurd or terrifying dreams. Their vision was often directly disturbed and they might be hallucinated or experience macropsia or diplopia.

The painful muscular cramps and tremblings that Delpech noted in 1856 could now be seen to form part of the widespread stimulation of the musculoskeletal system: some patients, for example, developed contractures of the hand much like writers' cramp that Delpech presumably thought to be a direct effect of mixing the solvent in the vats. 
The organs that above all were most predictably disturbed were the genitals: Delpech now refined his views considerably, finding that they too were frequently subject to excitation. "La stimulation des fonctions génératrices dans l'origine des accidents d'intoxication est un caractère remarkable sur lequel il est necessaire d'insister. Chez un grand nombre d'ouvriers en caoutchouc soufflé, ce symptôme s'est reproduit avec un intensité et une persistance d'ailleurs très variable. [Un] jeune homme de vingt ans, était poursuivi par des érections constantes et des besoins exagérés. Il se levant au milieu de la nuit et aller au loin chercher, dans des raprochements sexuels, la fin de cette obsession."

Such a state of affairs might only last for a short time or might more rarely persist throughout the illness. He had seen so few women workers that he was unsure if a similar process occurred in them: certainly their menstrual periods were much increased, so much so that some were unable to work at all during their periods.

The period of decline that followed the initial excitement represented the depression of the functions originally so stimulated. "Les maladies sont tristes, découragés, livrés à une indifferance absolue. Ils sont, disent-ils, comme hébétés. Ceux qui avaient quelque distinction quelque elegance, la perdent et se sentent en memes tomber dans l'abrutissement."

Memory failed so dramatically that many would forget even the simplest instructions. One worker pathetically told Delpech, "J'avais un réputation de raconter d'une manière amusant, je ne puis plus le faire maintenant ma langue tourne moins bien qu'autrefois."

The patients lost sensation in many parts of the body especially in the legs, indeed two men became completely anaesthetised over the entire surface of the body so that they were able to bathe in a cold river in November without complaint. Eyesight failed and patients were troubled by perceiving everything in a grey fog; in most cases only blanching of the optic disc could be observed, although a few patients also had corneal ulcers.

The increased sexual desire was replaced by almost universal impotence. So well known was this that no married man could be persuaded to take up employment in one large factory. When erections did occur they subsided so rapidly that coitus, let alone ejaculation, was impossible. Delpech speculated that the men were also sterile. One man talking of this reported, "J'étais très ardent, très coureur, avant d'entrer à l'atelier, moins rapidement je me mis à fuir les occasions tout par absence de désir que par conscience de ma faiblesse."

Children exposed to carbon disulphide experienced major disruption of their sexual maturation. A boy of 12 employed in the industry never experienced any sexual desire whereas a man of 20 who had worked in a factory since the age of 10 had a normal sized penis but atrophic testes. Women experienced lack of desire and occasional complete sexual anaesthesia so that many were abandoned by their husbands. None ever had full term pregnancies.

Delpech discusses only briefly the paralyses that developed in this phase. It might well affect only one muscle or one group in ways not observed in other poisonings-for example, the left side of the abdomen was especially affected. Almost all the case reports detail paralyses; almost half the patients became hemiplegic or paraplegic at some stage during their illness.

These observations led Delpech to speculate on the underlying aetiology. Superficially the course $i$ resembled that of other poisonings, of anaesthetic $\vec{\infty}$ agents, and of alcohol, particularly the phase of $c$ excitement preceding decline and collapse. In carbon 욱 disulphide intoxication, however, one striking $\rightarrow$ feature was that functions might resist suppression for longer periods than others: this suggested a constitutional factor on which the "poison" worked.

Some symptoms could be most readily explained as the direct effects of contact with carbon disulphide. When a small amount was placed on the skin there was first a sensation of unpleasant coldness succeeded by a feeling of heat followed by burning and extreme pain. Perhaps the vapour hanging near the floor first affected the legs in a similar way. Certainly when carbon disulphide was mixed with blood it reacted strongly to remove phosphorus from it and bound itself to fat globules. Delpech used this insight to construct his treatment regime of administering phosphorus, reasoning that it was its loss from the blood that caused the anaemia and from the brain that led to the mental depression.

The most important observation made by Delpech was that death was never an outcome of poisoning alone. Only one of his reported cases died and this was as a result of rupture of an aortic aneurysm. This was the only such outcome of which Delpech knew. One other patient, Madame L "se suicida sans motif apparent . . . son intelligence s'était alterée progressivement dupuis son entrée à l'atelier. On pensa N qu'elle s'était asphyxiee dans un acces d'alienation mentale."

For the most part cure or at least partial cure could be effected by moving the patients from their work. Indeed, if they returned to it they tended to become ill more quickly than before.

In the monograph Delpech emphasises the importance of avoiding contact with carbon disulphide: it is clear from the cases he reports, however, that prolonged contact, particularly among those aged over $\mathbf{4 0}$ tended to leave the patient chronically disabled by impaired memory.

As he had explained in his preliminary communication, the most important concern was to ensure 
adequate standards of ventilation and hygiene to prevent intoxication. His patient Monsieur D followed his ideas so closely that he radically redesigned the workshop. He divided up the factory into small "cupboards" fronted by glass. Holes were cut into the boxes through which the workmen could place their arms and carbon disulphide was only handled inside. The process of vulcanising items was divided into components with a man performing a single task. Finally, all equipment and the articles themselves were left to dry in the open air. Perhaps understandably, his fellow workers and the factory owners treated his efforts derisively. His boxes were called "magic lanterns" and his initiative was ignored. Only the simplest changes could ever be made without statutory obligations.

\section{Animal studies}

Delpech's experiments on animals represent one of the earliest approaches to inhalational industrial toxicology. They are also further evidence of the firm observational basis of all his work on carbon disulphide. The communications of 1856 and 1863 contain accounts of a series of careful experiments. Whereas the design of these experiments was virtually perfect, their execution was not and the account of their failure is a further testimony to Delpech's extraordinary honesty. Differences between the series also emphasise the development of his ideas on the pathology and physiology of the intoxication.

\section{Accidents produit par l'inhalation de sulfure de carbone en vapeur expériences sur les animaux ${ }^{8}$}

For these experiments reported in 1856, a box was constructed with a capacity of $0.5 \mathrm{~m}^{3}$. It was firmly jointed and covered with glass on its upper surface. Four hoses, each $1.5 \mathrm{~cm}$ in diameter, allowed what Delpech thought to be a sufficient amount of air to enter the box. Two pigeons were placed in the box and once they had survived happily for a few days a tablespoon of carbon disulphide was placed in a glass in the box. After only eight hours one bird had died and, following the introduction of a similar amount, the second succumbed also.

Delpech noticed that the birds had certainly eaten grain splashed by the solvent and had in fact probably died from suffocation because insufficient air entered the box. Accordingly the box was modified with the addition of a number of small holes in the sides and bottom, and a container was fixed to the sides to allow carbon disulphide to be safely introduced without contaminating the food.

A rabbit was subsequently exposed to $4 \mathrm{~g}$ of carbon disulphide and as doses were repeated it first developed convulsions and then weakness of the hind legs leading eventually to paralysis. This allowed
Delpech to state, "Cette expérience ne pouvait laiser de doute sur l'intensité des effects produits par cette substance chez les hommes et chez les animaux, et elle isolait bien nettement son action." $\mathrm{He}$ was impressed by the presenting disturbance of motility and the primary effect on the hind quarters that closely resembled the complaints of exposed workers.

The rabbit was allowed to recover and then replaced in the box with $12 \mathrm{~g}$ of carbon disulphide whereupon it gradually became incapacitated by a dense hemiplegia that followed several convulsions. It eventually died despite Delpech's attempts to revive it with warmth and brandy.

When examined, the lungs were obviously inflamed and the heart filled with black, unorganised clots. The liver was fatty and like the intestine showed discoloration secondary to postmortem changes. The urine smelt heavily of carbon disulphide, was alkaline, and loaded with albumin.

Delpech embarked on the experiments having recognised that his descriptions of the human symptoms were not specific to carbon disulphide but could be produced by toxic exposures to several chemicals in the environment. The initial animal studies were an attempt to produce some specific signs that were caused by carbon disulphide alone. Viewed objectively he failed in this, presumably because the animals were exposed to huge concentrations and, in fact, perished either of asphyxiation or of acute intoxication.

The animal experiments became of greater importance after his recognition of the excitatory and inhibitory phases. Furthermore, he recognised that any specific role for carbon disulphide could be proved only by excluding effects from those due to interactions with other substances-for example, sulphur chloride in the vulcanising mixture.

\section{Second animal experiments ${ }^{1}$}

For the experiments reported in 1863, a much larger box was made 1 metre high, 0.5 metres in length, and 1 metre wide. The interior of the box could be divided horizontally in two by a glass shelf thus allowing two animals to be exposed simultaneously to different concentrations. The solvent was introduced via reservoirs so that the animals were undisturbed and larger holes in the side of the box improved the general ventilation.

In the first experiment $30 \mathrm{~g}$ of sulphur chloride evaporated in the box in six hours and a rabbit showed no ill effects even after two days exposure. Subsequently, $30 \mathrm{~g}$ of carbon disulphide killed the same animal which had developed paralysis having been placed on the floor of the box for two days. Carbon disulphide was substantially more volatile and evaporated so rapidly that the concentration must, Delpech reasoned, be much higher than that of 
the sulphur chloride.

On this basis, Delpech reasoned that sulphur chloride alone could not produced all the adverse effects. This confirmed the observations that he had made at the factories. The chemical could certainly produced headache and considerably irritate the bronchus (particularly if it decomposed to hydrochloric acid) but it produced no long term harm in man or in animals.

In the succeeding experiments he took great pains to examine the effects of the mixture of sulphur chloride and carbon disulphide. In proportion of ten parts of sulphur chloride and 90 parts of carbon disulphide, a rabbit died rapidly, probably, as a postmortem finding disclosed, from a combination of suffocation and the effects of the solvent.

Accordingly, Delpech considerably decreased the amount of solvent that he introduced into the box, at the same time decreasing the proportion of sulphur chloride to carbon disulphide to one part in a hundred. Over the succeeding three days another healthy young rabbit was exposed to repeated doses of the mixture, becoming increasingly agitated. Indeed, one night its cries were so loud that someone who lived 60 yards away complained that his sleep was disturbed. This animal too eventually perished.

Further experiments showed that rabbits rapidly became paralysed by carbon disulphide but had no substantial symptoms when exposed only to sulphur chloride even when the fumes of the sulphur chloride were so dense as to resemble a fog. Furthermore, careful analysis of the results of mixing the solvent and the sulphur chloride showed no evidence of any chemical reaction that might be responsible for producing a third toxic compound.

The animal experiments did not, by 1863 , represent an attempt to reproduce in the rabbit signs identical with those demonstrable in man. Delpech seems to have accepted that the development of paralysis of the hind legs was an equivalent of the human weakness and tremor so pronounced in the legs. This allowed him to move beyond simply exposing the animals and observing their behaviour to testing complicated hypotheses with paralysis as a recognised end point.

Delpech introduced into his practice the use of phosphorus in the treatment of the intoxication not only because of its stimulation of the organism in other diseases but also because of his aetiological theories. In all cases there was a general improvement, particularly in the restoration of sexual potency and function.

\section{"Carbon disulphide neurosis"}

In his discussion of the mode of action, Delpech saw clearly that the direct effects of carbon disulphide were similar to those of alcohol and of the general anaesthetics (indeed, before the introduction of chloroform, carbon disulphide had been suggested as an alternative agent). The period of excitement occurred initially followed by a progressive depression of function. He pursued the analogy of the central effects of the anaesthetics into a direct effect on the peripheral nervous system of carbon disulphide vapours. He was thus able to account for the symmetry of the distal weakness and loss of sensation and its pronounced effects on the legs.

His accounts of the psychological manifestations of the intoxication remain vivid largely because he did not speculate on them from within the framework of contemporary psychiatry. It is striking, for example, that most of the phenomena he described were those that were being vigorously debated in French psychiatric publications in the 1840 s and 1850 s. $^{9}$ By placing his discussion firmly within the organic he avoided controversy, albeit unwittingly. It seems likely that his work on carbon disulphide was accepted as authoritative until Charcot's critique because it was read largely by physicians rather than by alienists. Charcot's contribution is largely misunderstood because the audience reading it now is predominantly interested in carbon disulphide and not in "hysteria": for example, Braceland suggests that he "beclouded" the issue and this has been the traditional view of this contribution. ${ }^{10}$

Intoxication par le sulfure de carbone ${ }^{11}$

In his demonstration of 6 November 1888 Charcot displayed a man who had been admitted to hospital with carbon disulphide poisoning. In his introduction he pointed out that between 1856 and 1863 Delpech had changed his views to suggest that carbon disulphide caused a specific identifiable disease rather than causing symptoms common to several other intoxicants. Charcot's examination of this patient led him to no such conclusion; indeed, he asserted, playing on the contemporary confusion, that Delpech's "carbon disulphide neurosis" was nothing but a simple case of "vulgar neurosis."

Charcot's patient was a previously healthy and $\frac{D}{0}$ vigorous 60 year old man of a sober disposition never given to excesses: like all carbon disulphide workers $\mathrm{N}$ he was forbidden to drink alcohol. There was no neuropathic trait in his family which included several $N$ centenarians. Since 1872 he had worked as a general $\omega$ labourer and in a vulcanising factory. In the four months before the illness he had been working in a factory cleaning out the vats that contained the $\mathbb{D}$ vulcanising mixture.

Quite suddenly one afternoon he collapsed unconscious "comme frappé d'apoplexie." He had suddenly been overcome by a feeling of suffocation and a burning pain in the scrotum. He was rescued by his $\triangle$ friends who thought him suffocated and he remained $\overline{2}$ unconscious for half an hour. Confused and bewildered he was taken back to his bed where he remained 
for two days. On the third day he noticed that his right arm felt heavy and by the evening it was completely paralysed. Gradually his right leg became heavy and weak; he could walk only with difficulty. The case closely resembled those described by Delpech.

Charcot demonstrated the neurological findings to his audience offering a commentary at the same time. It is an interesting observation that despite the frequency with which the paper is quoted, its continual confusion between right and left, caused by faulty proof reading, has not been previously noted.

The man dragged his leg behind him as if it were inert and lifeless: he made no attempt to move it nor did he circumduct the limb when he was walking as would be the case "dans un hémiplegie ancienne de cause organique." The right arm was supple, undeformed, and without rigidity. The hand, however, was deformed, being held with the fingers at right angles to the palm so strongly as to resist movement. Charcot pointed out that usually in organic paralyses the fingers were folded over or hooked ("en crochet"). The reflexes were not exaggerated in either limb. There was complete loss of sensation down the right side (sparing, according to the published illustration, part of the abdomen and the flexor surface of the arm); this also extended to the underlying structures. It was important to notice that while sensation was completely abolished, motor function was not. This differed from the example of lesions in the posterior limb of the interior capsule. More remarkably the face was not affected by the motor loss. One could readily note a frequent twitching of the angle of the right side of the mouth downwards and to the right. Charcot had described in his previous work all these features as being classically found only in hysteric paralyses, particularly the mismatch between motor and sensory loss and the "spasme glosso-labiale." The special senses were all directly affected on the right side. The visual field of the right eye was greatly diminished as was hearing and the sense of taste on the right side of the tongue.

The man's mental state was particularly worthy of note. Charcot had taught that female hysterics failed to respond to their disabilities in a "normal" manner: they all reacted with "belle indifference" (or as he graphically expresses it here "brio morbide"). Among men, particularly of the working class, the situation differed; they were always "gens sombres, mélancholiques, déprimés, déscouragés."

The present patient was no different. Whereas he had never been jolly he had always responded to life's difficulties without complaint. He was not utterly inconsolable. Since the accident he had experienced the most terrifying dreams; he was chased by lions, wolves, or fantastic creatures or he took refuge from a flood only to see the water covering the mountain on which he stood. This was so different from hysteria, at least superficially, that some authors had suggested that the condition ought to be called "neurose traumatique." But all the symptoms were entirely characteristic of hysteria caused by trauma or intoxication. Indeed, almost all the symptoms discussed by Delpech similarly fitted into the same category. Only some isolated nerve lesions, just like those observed in lead or alcohol poisoning, seemed to result from poisoning by carbon disulphide itself.

\section{Sulfure de carbone et hysteria ${ }^{12}$}

In 1888, three days after Charcot's demonstration, Marie read a paper to the Sociéte Médicale des Hôspitaux in which he continued the attack on Delpech. He presented the same patient as Charcot and a man of 36 with almost identical symptoms.

Marie elaborated the theoretical links between carbon disulphide poisoning and the development of hysteria. All the cases of neurological symptoms presented by Delpech were, as Charcot had shown, understandable only as functional disorders. Delpech had ignored the strict demarcation of the loss of sensation and the curious distribution of the motor deficits. When paralyses occurred they never led to contractures nor were the muscles flaccid. Occasionally all four limbs might be paralysed in ways rarely seen in organic illnesses. It was strange, he remarked, that so many of the symptoms of the reported poisonings occurred on the right side of the body. Finally, the disturbance of sexual functioning often first manifested by increased desire was only seen in hysteria.

Marie's conclusion was similar to Charcot's: the peripheral neuropathy that could be demonstrated clinically was one manifestation of carbon disulphide intoxication and the "toxic hysteria" was the other.

\section{Charcot and hysteria}

In conventional accounts of carbon disulphide poisoning, authors almost always mention the work of Charcot and Marie either in a neutral, perhaps embarrassed tone $e^{4}$ or in a dismissive on $e^{10}$ whereas Delpech is presented as describing the significant features of carbon disulphide poisoning. As early as 1905, Jump and Cruice reinterpreted all the clinical signs in Marie's cases as resulting from isolated peripheral neuropathies. ${ }^{13}$ They ignore the fact that Charcot and Marie themselves had emphasised that neuropathies could easily be shown by objective clinical investigations-for example, by electrogalvanic stimulation. Jump and Cruice and many other authors practised in a neurology radically altered by the successes of Charcot and Hughlings Jackson, one in which the functional disturbance occurring without structural abnormality was unreal, fabricated, or psychological.

Unfortunately a reading of Delpech, who practised 
before the "invention" of modern neurology, by those after its creation, paradoxically makes him seem a contemporary and makes Charcot seem misguided. A more careful consideration must take into account the theoretical practices of both men.

Delpech, as we have noted above, operated within the tradition of careful, painstaking observation of patients and of attempts to define relations between different pathological entities. The nosologies derived were as elegant and complicated as the Linnean classification of species (on which, indeed, they were based). The reference points for carbon disulphide intoxication were the acute effects of the anaesthetics and the symptoms of chronic lead poisoning. Between 1856 and 1863 Delpech had identified a series of closely related diseases differing from one another according to their severity and duration as much as their outcome.

In general Delpech shows no great interest in the morbid processes causing the symptoms (probably due in part to the absence of postmortem material). Such an attitude, labelled by Lopez-Pinero and others as the physiopathological view, ${ }^{14}$ developed out of the failure of anatomy and pathology completely to described many diseases, particularly the large group designated then as neuroses. Delpech, with his emphasis on precise changes in function and his repeated use of "excitation" and "suppression," follows a tradition derived from Broussais and Roche writing more than 20 years earlier. Accordingly, his continued references to anatomical structures do not have the same significance as those by Charcot. Delpech would hold that function, the result of deranged physiology, was the only way of understanding the intoxication whereas Charcot always sought an anatomical lesion. Even the animal experiments that so closely resemble those of contemporary toxicology have a different purpose: Delpech was clearly trying to replicate the form of the illness, not its pathology.

By 1882 the anatomicoclinical method had triumphed over the approach that concentrated on function. Charcot's own work, which correlated the clinical presentation of multiple sclerosis with brain changes, was central to this as was his concept of the "lesion." His work on hysteria, described as his "crowning moment and denoument"14 was an attempt to explore the area of the neuroses, then understood as abnormalities of nervous function.

Charcot had been interested in functional neurological illness from the earliest phase in his career, when he was an interne at the Salpetriére. On the ward, caring for convulsive patients, he learnt to distinguish between those patients suffering from epilepsy and those who were not. As he investigated the latter group he began to describe some whose convulsions formed part of a hysterical crisis. In 1882 he showed the similarity between the phases of these hysterical crises and the stages of the hypnotic state. This suggested that similar processes were operating in both groups.

By 1884 he had observed that it was possible to recreate the symptoms of hysterical paralyses (presenting after accidents, for example) using hypnotic suggestion in susceptible subjects. A smal proportion of individuals seemed to live in a permanent somnambulistic state so that hypnotism was not even necessary, whereas for others the state had to be induced. He called the resulting paralyses "dynamic" and opposed them to the organic paralyses, the outcome of direct damage to the nervous system. ${ }^{15} 16$

Freud, who studied under Charcot in the winter of 1886-7, explained the process whereby a postraumatic paralysis could develop. " "We will take the case of a person who is subjected to a trauma without having been ill previously and perhaps without even having any hereditary taint. The trauma must fulfil certain conditions. It must be severe-that is, it must be of a kind involving the idea of mortal danger. But it must not be severe in the sense of bringing physical activity to an end. Moreover, the trauma must have some relationship to some part of the body. Let us suppose that a heavy billet of wood falls on a workman's shoulder. The blow knocks him down, but he soon realises that nothing has happened and goes home. After a few weeks ... he wakes up one morning and notices that the arm that was subjected to the trauma is hanging down limp and paralysed, though in the interval . . he has made perfectly good use of it ... The workman was not in a state of hypnosis. Nevertheless we may assume that he was in a special state of mind during the trauma; and Charcot is inclined to equate that effect with the artificially induced state of hypnosis. This being so, the traumatic spontaneous paralysis is completely explained and brought into line with the paralysis produced by suggestion, and the genesis of the symptom is unambiguously determined by the circumstances of the trauma." 18

Freud's own development of Charcot's theory (which led on into psychoanalysis) had already, by 1893, suggested to him that functional disorders had their sources in psychological disorder. ${ }^{19}$ Indeed after Charcot's death almost all his work on hysteria fell into disrepute; only his theories on posttraumatic neurosis continued to exercise influence.

This has obscured the precise way in which Charcot and Marie were using phrases such as hysteria and neurosis. They referred to the results of lesions too subtle or perhaps too short lived to be detected in the brain at necropsy and were in some way related to the psychological state of the person at the time of their origin. It was the continued failure of all attempts to demonstrate the lesions and the obscurity of their causes that led to the failure of the theory. 
Nevertheless, we may reconstruct the aetiology that Charcot proposed for the effects of carbon disulphide. Because of its acute effects, the solvent induced a psychological state in the men, virtually identical with that of hypnosis, in which lesions could develop in the central nervous system. These, not caused by the carbon disulphide, could lead on to the hysterical paralyses observed. The entire clinical picture was a compound of the effects of these lesions and the peripheral neuropathy. Marie could state with obvious satisfaction "les neurites périphérique et 'hysteria toxique' sont functions des memes intoxications. Peut-être cette notion permettra-t-elle de pénétrer plus avant dans les arcanes de l'hysteria pouvrant bien tirer, elle aussis, son origine de véritable lesions des centres nerveaux." 12

\section{Psychiatry of carbon disulphide poisoning after Charcot}

For most of this century hysteria and neurosis have had as their causes psychological factors that produce no physical effects. In reports on carbon disulphide "functional disability" was increasingly ignored as increasing attention was paid to other consequences of poisoning, such as optic neuritis. ${ }^{20}$ Whereas Delpech was honoured because of priority, Charcot's contributions were cited perhaps because of his vast importance in neurology.

In the 1880s the chief use of carbon disulphide was in the viscose rayon industry. From the late 1880 s cold vulcanisation was performed using sulphur chloride vapour rather than a solution. In the churn rooms of the rayon process the ambient concentration of carbon disulphide was much lower than in the vulcanisation sheds of the $1860 \mathrm{~s}$; the major danger occurred with the opening of the churns and their cleaning.

Jump and Cruice reported the symptoms of two men from the Artifical Silk Works in Philadelphia. ${ }^{13}$ In both, major disturbances of mood and behaviour dominated their mental state. Only one had abnormal findings on neurological investigation; the other, complaining of vertigo and formication, had no objective signs.

The major feature of true carbon disulphide poisoning was, in their view, that of a peripheral neuritis closely resembling that of alcoholic neuritis (now recognised as a symptom of thiamine deficiency). They conclusively demolish Marie's argument about his own cases while maintaining that "peculiar manifestations of hysteria" can be observed with the neuritis. The psychiatric abnormalities were, in their view, the direct toxic effects of exposure to the solvent. Despite reviewing Delpech's 1863 monograph they nowhere comment on his ideas of the two stages.

While the neurology of carbon disulphide was being classified, its psychiatry was becoming ob- scure. According to Braceland, ${ }^{\mathrm{f} 0}$ an often unreliable authority, Laudenheimer in a monograph of 1899 suggested that carbon disulphide acted as "an exogenous poison that might initiate a psychosis." In an uncited work Rodenacker was credited with the view that some personality types, particularly those with cyclothymic traits, were particularly susceptible to its adverse effects whereas others were insensitive. Unnamed opponents by contrast suggested that the psychotic symptoms were the direct effects of the solvent, were specific to it, and differed in form from functional psychosis.

The synthesis of these views was produced in the monograph of Bonhoeffer. ${ }^{21}$ Its publication in the German Monatschrift für Psychiatrie und Neurologie ensured that it has been forgotten by occupational physicians. His detailed examination of several cases led him to define several disease entities on the basis of the phenomenology and course.

There was no doubt that even in small quantities the solvent produced a peripheral neuropathy most pronounced in the sensory modalities. Similar direct effect could be observed, he suggested, in the Parkinsonian syndrome equally common among this group of solvent workers. A toxic psychosis whose primary symptoms were clouding and fluctuation of level of consciousness, impairment of memory, and mood disturbance could be produced after repeated exposure to high concentrations. In most cases this resolved after a few months and certainly within a year. Rarely, the acute psychosis was extremely severe in which case the sufferer would be left permanently disabled with a "chronic psychosis of the Korsakoff type." Finally, in individuals predisposed by heredity or habit to a functional psychosis such as schizophrenia, carbon disulphide could hasten its development even when a toxic psychosis did not develop first. In such cases the prognosis was no different from other causes of the same psychosis.

This view was popularised by Braceland's 1941 review that preceded his own study of the effects of the solvent on a group of 90 rayon workers. ${ }^{10}$ Two outcomes seemed to be common among these men working in a factory manufacturing collars. One group developed symptoms entirely characteristic of a toxic psychosis after a brief prodromal illness; they generally recovered completely. A small proportion, however, developed mental disorders, not necessarily psychoses, that were perhaps functions of a pre-existing disposition. Almost all his patients were hallucinated and deluded at least for a time after leaving the churn rooms. In Braceland's view hysteria was unlikely to account for any significant part of the symptoms, the effects being purely those of intoxication.

In the past 20 years this constant theme of devaluing or ignoring the functional has become dominant in occupational psychiatry so much so that it has 
seemed to become an annex of neurology. The recent concerns about other solvents causing psychiatric disease reflect this, resulting in some confusion when psychiatric symptoms do not coincide completely with physical findings, generally signs of cerebral failure. Yet any true occupational psychiatry must find such problems to be its true subject: it is in these functional cases that the significant difficulties may best be shown.

One case of Delpech's series illustrates this particularly well. The man was admitted in December 1860 with right sided paralysis after a sudden attack that had been followed by seven days unconsciousness. Delpech originally assumed that he had suffered from a left side cerebral haemorrhage. In February 1862 he was readmitted with extensive erysipelas. In the course of this illness the paralysis lessened and he regained function of his hand and his foot. He was discharged "satisfaisant." One could have supposed, Delpech said, that the violent inflammation of the erysipelas had led to a resolution of the haemorrhage. Perhaps a more modern explanation would concentrate on the circumstances of the cure, both the powerful effect on a labourer of the eminent physician's personal attention and the consequences of successful litigation against an employer.

Even in Delpech the elements of the patient's symptoms seem to be an amalgam of the physical and the psychological. In the 50 years since Bonhoeffer's paper a crude organic model has persuaded occupational psychiatrists that disorders of psychological functioning are identical with those of brain functioning and only recently has its failure as a model been recognised as such.

1 Delpech ALD. Industrie du caoutchouc souffle. Recherches sur l'intoxication speciale que determine le sulfure de carbone.
Annales d'Hygiene Publique 1863;19:65-183.

2 Zeldin T. France 1848-1945: ambition and love. Oxford: Oxford University Press, 1979.

3 Tournier SL. Auguste Louis Dominique Delpech. In: Dictiona-O ire de biographie Francais. Tom X. Paris: Libraire Letouzay et Ane, 1965.

4 Pickles SS. The production and utilization of rubber. In: Singer C, Holmyard EJ, Hlal AR, Williams TL, eds. $A$ history of $\vec{\nabla}$ technology. Vol 5. London: Oxford University Press, 1958.

5 Hunter D. The diseases of occupation. London: Churchill Livingstone, 1979.

6 Delpech ALD. Une note sur les accidents qui developpe chez les $\overrightarrow{0}$ ouvriers en caout-chouc, l'inhalation de sulfure de carbone. Gazette Hebdomadaire de Medecine et Chirurgie 1856;3:40-2. $\overrightarrow{\vec{\omega}}$

7 Delpech ALD. Accidens que developent chez les ouvriers en $\vec{\omega}$ caoutchouc l'inhalation du sulfure de carbone en vapeur. L'Union Medicale 1856;10:265-7.

8 Delpech ALD. Accidents produit par l'intoxication de sulfure de $\frac{\mathbb{N}}{3}$ carbone en vapeur experience sur les animaux. Gazette Hebdomadaire de Medecine et Chirurgie 1856;3:384-6.

9 Berrios GE. Delirium and confusion in the 19th century. $\mathrm{Br} J \mathrm{~W}$ Psychiatry 1981;139:439-49.

10 Braceland FJ. Mental symptoms following carbon disulfide $\vec{\infty}$ absorption and intoxication. Ann Intern Med 1942;16:246-61.

11 Charcot JM. Intoxication par le sulfure de carbone. In: Les lecons 은 du mardi a la salpetriere 1887-1888. Paris: Delabage et Lacarnier, 1887:43-53. 12 Marie P. Sulfure de carbone et hysterie. Societe Medicale des
Hopitaux 1888;6:445-54.

13 Jump HD, Cruice JM. Chronic poisoning from carbon disul- $\widehat{\widehat{O}}$ phide. University of Pennyslvania Medical Bulletin 1905; 17:193-6.

14 Lopez-Pinero J. The concept of neurosis. Cambridge: Cambridge University Press, 1986.

15 Ellenberger $\mathrm{H}$. The discovery of the unconscious. New York: Basic Books, 1970.

16 Drinka GF. The birth of neurosis. New York: Simon and Schuster, 1984.

17 Jones E. The life and work of Sigmund Freud. Vol 1. The young $\bar{\partial}$ Freud. London: Hogarth Press, 1972.

18 Freud S. The mechanism of hysterical phenomena. In: The $\frac{\mathrm{Q}}{\mathbb{D}}$ standard edition of the complete psychological works of Sigmund $\varrho$ Freud. Vol II. Early psychoanalytic publications. London: $\vec{\overrightarrow{ }}$ Hogarth Press, 1975.

19 Critchley EMR, Cantor HE. Charcot's hysteria renaissant. $\mathrm{Br}$ Med J 1984;289:1785-8.

20 Frost A, Gunn, Nettleship. Report on poisoning by bisulphide of carbon and sulphur chloride. Lancet 1985;i:113.

21 Bonhoeffer K. Ueber die Neurologischen und Psychischen $\bar{\partial}$ Folgerscheinungen der $\mathrm{CS}_{2}$ Vergiftung. Monatschrift für $\stackrel{\mathbb{D}}{\mathrm{S}}$ Psychiatrie und Neurologie 1930;75:195-213.

Accepted 28 June 1989 